\title{
sciendo
}

\section{REDOX STATUS, HEMATOLOGICAL PARAMETERS AS WELL LIVER AND KIDNEY FUNCTION INDICATORS IN BLOOD OF CHICKENS RECEIVING GOLD NANOPARTICLES*}

\author{
Iwona Sembratowicz*, Katarzyna Ognik \\ Department of Biochemistry and Toxicology, Faculty of Biology, Animal Sciences and Bioeconomy, \\ University of Life Sciences in Lublin, Akademicka 13, 20-950 Lublin, Poland \\ •Corresponding author: iwona.sembratowicz@up.lublin.pl
}

\begin{abstract}
The aim of the study was to assess the biocompatibility of gold nanoparticles (Au-NPs) for chickens by investigating their effect on their growth, hematological parameters, markers of oxidative stress, and indicators of liver and kidney function. The experiment was carried out on 54 chickens assigned to 3 experimental groups of 18 birds each. The control group did not receive gold nanoparticles. The birds in group $\mathrm{Au}-\mathrm{NPs}_{2.0}$ received gold nanoparticles in a tube into a crop at a rate of $2.0 \mathrm{mg} / \mathrm{kg}$ body weight/day, while the birds in $A u N P s_{5.0}$ group at a rate of $5.0 \mathrm{mg} / \mathrm{kg} \mathrm{body}$ weight/day. The blood for analysis was collected after 7, 14, 21 and 28 days of Au-NPs application. The obtained results indicate that short-term (7-14 day) exposure to lower dose (2.0 $\mathrm{mg} / \mathrm{kg} \mathrm{b.w./}$ day) of AuNPs had no toxic impact on chickens, but the extension of the duration time caused toxicological effects evidenced by growth inhibition as well as induction of oxidative stress and liver injury. The higher dose of AuNPs $(5.0 \mathrm{mg} / \mathrm{kg}$ b.w./day) exerted toxic effects already after 7-14 days of supplementation.
\end{abstract}

Key words: nano-gold, biocompatibility, toxicity, oxidative stress, blood indices, chicken

According to the American Society for Testing and Materials (2006), the term "nanoparticles" refers to particles of which at least one dimension is less than $100 \mathrm{~nm}$. Reducing the dimensions of particles increases their surface-area-to-volume ratio and the proportion of atoms exposed to the outside, which in turn increases their chemical reactivity and gives them physicochemical properties distinct from those of traditional materials (Nel et al., 2006). Gold nanoparticles (AuNPs) have been used as biosensors, in photothermal and cancer therapy, in drug delivery, and in the treatment of rheumatoid arthritis (Siddiqi and Husen, 2017). Some experiments have revealed antimicrobial properties of AuNPs against many pathogenic bacteria strains such as

\footnotetext{
*Work financed from statutory activity, project no. ZKT/DS-3.
} 
Escherichia coli, Staphylococcus aureus, Bacillus subtilis, Klebsiella pneumonia, and Salmonella typhimurium (Shamaila et al., 2014; Surekha, 2017). Because AuNPs do not induce bacterial resistance it may be an alternative to antibiotics (Li et al., 2014). AuNPs can also serve as adjuvants to improve the effectiveness of vaccination by stimulation of antigen-presenting cells and controlling release of antigens (Dykman and Khlebstov, 2017). Studies on mice (Sengupta et al., 2013; Małaczewska, 2015) and also on chickens (Sembratowicz and Ognik, 2018) have revealed that AuNPs possess capacity to enhance a humoral and cell-mediated immune response. Due to their antimicrobial and immune-modulating properties there is a possibility of using AuNPs in poultry production. The studies conducted by Zielińska et al. (2011 a, b) have shown that AuNPs administered in ovo for chickens, positively influenced muscle development during embryogenesis without causing toxic effects. In another study, Pineda et al. (2012) reported that they did not negatively affect chicken embryos growth and development. Sawosz et al. (2010) also stated no abnormalities in the development of chicken embryos treated by AuNPs and, moreover, did not detect their pro-inflammatory activity. The main advantage of AuNPs is that they are easy to synthesize by chemical reduction technique and are also characterized by a low toxicity compared to other nanomaterials (Shamaila et al., 2014). Both in vitro research on populations of murine and human cells and in vivo experiments have shown high biocompatibility of AuNPs (Connor et al., 2005; Shukla et al., 2005; Jo et al., 2015). However, many experiments have proved toxic effect of AuNPs for living organisms (Cho et al., 2009; Alkilany and Murphy, 2010; Yah, 2013). Due to their small size, nanoparticles (NPs) can easily penetrate biological membranes, reach individual cells and organs, where they may accumulate and contribute to significant injuries or dysfunction (Unfried et al., 2007). Metal NPs may be the cause of oxidative stress (Pan et al., 2009), inflammation (Schrand et al., 2008; Sembratowicz and Ognik, 2018), hematological alterations (Abdelhalim and Moussa, 2012), modification of proteins (Saptarshi et al., 2013) and autoimmune reactions (Zolnik et al., 2010). All of these effects complicate in vivo application of AuNPs. It should be noted here that the biological effects of nanoparticles depend on numerous factors, such as dose, diameter, shape, aggregation and surface coating (Dobrovolskaia et al., 2009; Alkilany and Murphy, 2010; Abdelhalim and Moussa, 2012; Yah, 2013). Other important factors include time and route of exposure, the kind of animal, uptake, metabolism, excretion and immune response (Zhang et al., 2010, 2011; Xu et al., 2013).

Most research on the biological activity of AuNPs has been conducted on experimental animals (mice and rats), while the data about the impact of their application in poultry is insufficient. We assumed that the bird's response to AuNPs exposure is similar to mammals and may be manifested by the occurrence of oxidative stress, development of inflammation, growth inhibition or disturbances of internal organs function. Therefore it was considered worth analyzing, how per os administration of different doses of AuNPs for chickens affects their growth, hematological parameters, markers of oxidative stress as well as indicators of liver and kidney function. This is a pilot experiment that will allow establishing a safe dosage level and duration time of AuNPs application for chickens in case of its use in the future. 


\section{Material and methods}

\section{Nanoparticles}

The subject of the study was an aqueous solution of a gold nanocolloid at a concentration of $50 \mathrm{mg} / \mathrm{l}$. Concentration of $20 \mathrm{mg} / \mathrm{l}$ was prepared from this solution for the purposes of the experiment. The AuNPs were non-ionic, nanocrystalline, chemically pure particles $5 \mathrm{~nm}$ in size, produced in a physical process (a non-explosive, high-current method for degradation of metals) by a unique patented technology licensed by Nano Technologies Group, Inc. (Chicago, Il, USA). All information about this product is included in European Patent Specification (EP 2081672 B1). AuNPs were characterized for size distribution and shape by using transmission electron microscope (TEM) Tecnai G2 T20 X-TWIN (FEI, Hillsboro, USA) and LEO 912AB (Carl Zeiss, Jena, Germany). TEM images have shown that nanoparticles possess the shape of plates having a thickness of 3-5 atoms (Figure 1), and the average size was estimated at about $5 \mathrm{~nm}$ (Figure 2).
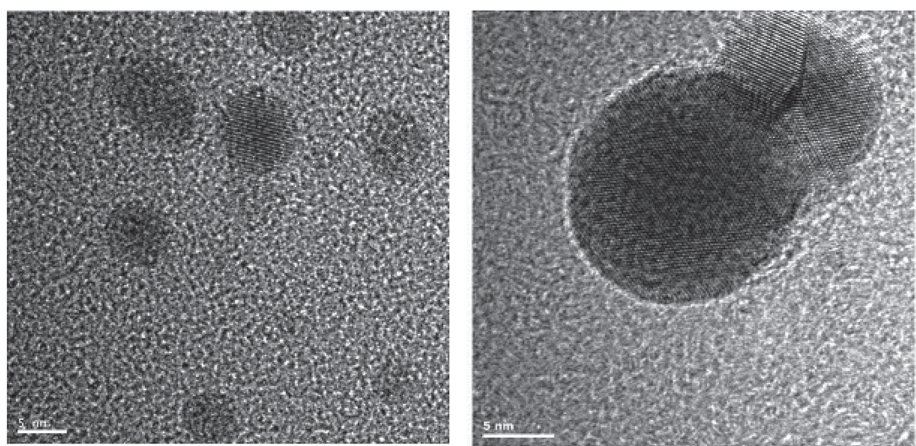

Figure 1. Transmission electron microscopy images of gold nanoparticles (Sembratowicz and Ognik, 2018)

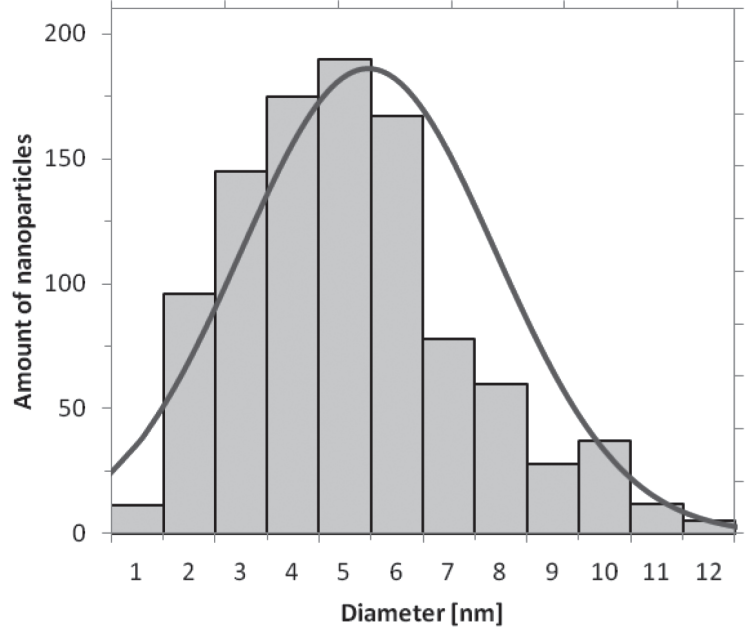

Figure 2. Hydrocolloid of gold nanoparticles size distribution (Sembratowicz and Ognik, 2018) 


\section{Animals}

The material for the study consisted of 7-day-old Ross 308 chickens ( $)$ raised until their 35th day of life. The experimental procedure was approved by the Second Local Ethics Committee for Experiments with Animals in Lublin (approval no. 30/2014). The birds were kept in pens on straw litter and reared in standard hygiene conditions in a building with regulated temperature and humidity. The chickens had permanent access to drinking water and received ad libitum complete feed mixes appropriate for the rearing period in accordance with feeding standards for poultry (Smulikowska and Rutkowski, 2005). The experiment was carried out on 54 chickens assigned to 3 experimental groups of 18 birds each ( 3 pens of 6 individuals each). The control group did not receive AuNPs. The birds in group Au-NPs ${ }_{2.0}$ received gold nanoparticles in a tube into a crop at a rate $2.0 \mathrm{mg} / \mathrm{kg}$ body weight/day, while birds in Au-NPs ${ }_{5.0}$ group at a rate $5.0 \mathrm{mg} / \mathrm{kg}$ body weight/day. The applied dose of gold nanoparticles was presented in Table 1.

Table 1. The applied dose of gold nanoparticles to chickens

\begin{tabular}{l|c|c|c|c}
\hline & & Control & $\mathrm{Au}^{-N \mathrm{Ns}_{2.0}}$ & $\mathrm{Au}-\mathrm{NPs}_{5.0}$ \\
\hline The dose of nano-gold applied (mg) & $2 \mathrm{wk}$ & 0 & 5.74 & 14.35 \\
& $3 \mathrm{wk}$ & 0 & 11.06 & 21.67 \\
& $4 \mathrm{wk}$ & 0 & 17.92 & 44.80 \\
The total nano-gold applied (mg) & $5 \mathrm{wk}$ & 0 & 25.20 & 63.00 \\
\hline
\end{tabular}

Control - not supplemented with gold nanoparticles; Au-NPs ${ }_{2.0}$ - supplemented with gold nanoparticles at $2.0 \mathrm{mg} / \mathrm{kg}$ body weight; Au-NPs ${ }_{5.0}$ - supplemented with gold nanoparticles at $5.0 \mathrm{mg} / \mathrm{kg}$ body weight.

\section{Blood analyses}

Blood samples (from 6 chickens from each group) from the wing vein were collected after 7, 14, 21 and 28 days of nano-gold application. An aqueous solution of heparin sodium salt at $0.01 \mathrm{ml}$ per $1 \mathrm{ml}$ blood was used to stabilize the blood samples. Hematocrit value $(\mathrm{Ht})$, hemoglobin level $(\mathrm{Hb})$, and white blood cell (WBC) and red blood cell (RBC) count were determined by standard methods. The Wintrobe method was used to determine the erythrocyte sedimentation rate (ESR) in the blood, i.e. the rate at which erythrocytes settle out of unclotted blood in one hour. In blood plasma the activities of alanine aminotransferase (ALT) and aspartate aminotransferase (AST) as well as uric acid (UA), urea (UREA) and creatinine (CREAT) contents were determined using kits developed by Cormay (PZ Cormay S.A. Poland). The contents of glutathione (GSH+GSSG) and the activities of antioxidant enzymes: superoxide dismutase (SOD), by the adrenaline method with a modification of the wavelength to $320 \mathrm{~nm}$ to increase the selectivity of transient reaction products, and catalase (CAT) were also determined (Bartosz, 2004). In addition, the blood plasma was analyzed for levels of lipid peroxidation products: peroxides (LOOH) according to Gay and Gębicki (2002) and malondialdehyde (MDA) as an end product of tissue lipid oxidation according to Salih et al. (1987). 


\section{Statistical analysis}

Numerical data were processed by the analysis of variance (ANOVA) and the results were presented as mean values for groups and standard error of mean (StatSoft Inc., 2011). Differences were considered to be significant at $\mathrm{P} \leq 0.05$ and $\mathrm{P} \leq 0.01$.

\section{Results}

All birds (from all groups) survived the experimental period, liveability was $100 \%$. Changes in body weight during the treatment are presented in Table 2. No significant decrease in body weight was observed in birds administered AuNPs at a dose $2.0 \mathrm{mg} / \mathrm{kg}$ until $21 \mathrm{st}$ day of the experiment. After 28 days of AuNPs application, a considerable $(\mathrm{P}=0.021)$ decrease in body weight of chickens occurred. In Au$\mathrm{NPs}_{5.0}$, a significant $(\mathrm{P}=0.042)$ lowering of body weight appeared earlier, already after 21 days of AuNPs supplementation. The results of the hematological parameters of the blood of chickens (Table 3) have shown that after 7 days of AuNPs application in group receiving higher rate, an increase $(\mathrm{P}=0.038)$ in WBC count was observed. In turn, after 28 days of the experimental period in this group WBC count decreased significantly $(\mathrm{P}=0.022)$, as compared to the control group. In $\mathrm{Au}-\mathrm{NPs}_{2.0}$ group after 21 and 28 days of AuNPs administration, a significant increase of WBC number was noted. Long-lasting, 21- and 28-day application of a higher dose of AuNPs has contributed to a decrease of $\mathrm{RBC}$ count $(\mathrm{P}=0.033$ and $\mathrm{P}=0.013$, respectively), $\mathrm{Hb}$ level $(\mathrm{P}=0.049$ and $\mathrm{P}=0.009$, respectively) and $\mathrm{Ht}$ value $(\mathrm{P}=0.038$ and $\mathrm{P}=0.042$, respectively). A drop in $\mathrm{Hb}(\mathrm{P}=0.047)$ concentration was noted earlier, after 14 days of supplementation of AuNPs. A significant decrease of $\mathrm{Hb}$ level and $\mathrm{Ht}$ value was observed always in Au-NPs ${ }_{2.0}$ group, after 21 and 28 days of AuNPs supplementation. In $\mathrm{Au}-\mathrm{NPs}_{5.0}$ group, for all of the experimental period the ESR value was significantly higher as compared to the control group, while in Au-NPs ${ }_{2.0}$ group, an increase $(\mathrm{P}=0.014)$ in ESR was noted only after 28 days of supplementation.

Table 2. The effect of gold nanoparticles administration on body weight $(\mathrm{g})$ of chickens

\begin{tabular}{l|c|c|c|c|c|c}
\hline \multirow{2}{*}{$\begin{array}{c}\text { Age } \\
\text { (weeks of life) }\end{array}$} & \multirow{2}{*}{$\begin{array}{c}\text { Days of } \\
\text { administration }\end{array}$} & \multicolumn{3}{c|}{ Treatments } & \multirow{2}{*}{ SEM } & P-value \\
\cline { 3 - 5 } & & Control & Au-NPs $_{2.0}$ & Au-NPs $_{5.0}$ & & \\
\hline 0 & 0 & 42 & 41 & 42 & 0.001 & 0.874 \\
1 & 7 & 147 & 148 & 146 & 0.012 & 0.582 \\
2 & 14 & 402 & 384 & 387 & 0.261 & 0.654 \\
3 & 21 & 759 & 753 & 722 & 0.294 & 0.127 \\
4 & 28 & $1220 \mathrm{a}$ & $1192 \mathrm{ab}$ & $1173 \mathrm{~b}$ & 0.634 & 0.042 \\
5 & $1783 \mathrm{a}$ & $1694 \mathrm{~b}$ & $1682 \mathrm{~b}$ & 0.358 & 0.021 \\
\hline
\end{tabular}

$\mathrm{a}, \mathrm{b}$ - means with different letters within a row are significantly different at $\mathrm{P} \leq 0.05$; $\mathrm{SEM}-$ standard error of mean, treatment group abbreviations: see Table 1. 
Table 3. The effect of gold nanoparticles administration to chickens on hematology indices

\begin{tabular}{|c|c|c|c|c|c|}
\hline Item & $\begin{array}{c}\text { WBC } \\
10^{9} / 1\end{array}$ & $\begin{array}{l}\mathrm{RBC} \\
10^{12} / 1\end{array}$ & $\begin{array}{l}\mathrm{Hb} \\
\mathrm{g} / 1\end{array}$ & $\begin{array}{l}\mathrm{Ht} \\
(\%)\end{array}$ & $\begin{array}{c}\text { ESR } \\
(\mathrm{mm} / \mathrm{h})\end{array}$ \\
\hline \multicolumn{6}{|l|}{7 days $^{1}$} \\
\hline Control & $23.95 \mathrm{~b}$ & 1.81 & 6.52 & 29.52 & $2.87 \mathrm{~b}$ \\
\hline $\mathrm{Au}-\mathrm{NPs}_{2.0}$ & $27.33 \mathrm{ab}$ & 1.79 & 6.44 & 30.21 & $3.05 \mathrm{ab}$ \\
\hline $\mathrm{Au}-\mathrm{NPs}_{5.0}$ & $29.20 \mathrm{a}$ & 1.75 & 5.91 & 29.27 & $4.19 \mathrm{a}$ \\
\hline SEM & 0.246 & 0.035 & 0.094 & 0.269 & 0.102 \\
\hline $\mathrm{P}$-value & 0.038 & 0.286 & 0.074 & 0.364 & 0.033 \\
\hline \multicolumn{6}{|l|}{14 days } \\
\hline Control & $23.34 \mathrm{~b}$ & 1.83 & $6.75 \mathrm{a}$ & 30.23 & $3.76 \mathrm{~b}$ \\
\hline $\mathrm{Au}-\mathrm{NPs}_{2.0}$ & $26.94 \mathrm{ab}$ & 1.70 & $6.31 \mathrm{ab}$ & 29.64 & $4.12 \mathrm{ab}$ \\
\hline $\mathrm{Au}-\mathrm{NPs}_{5.0}$ & $28.33 \mathrm{a}$ & 1.59 & $5.60 \mathrm{~b}$ & 29.14 & $5.38 \mathrm{a}$ \\
\hline SEM & 0.361 & 0.022 & 0.255 & 0.487 & 0.098 \\
\hline $\mathrm{P}$-value & 0.042 & 0.145 & 0.047 & 0.728 & 0.021 \\
\hline \multicolumn{6}{|l|}{21 days } \\
\hline Control & $22.88 \mathrm{~b}$ & $1.90 \mathrm{a}$ & $6.88 \mathrm{a}$ & $31.74 \mathrm{a}$ & $4.14 \mathrm{~b}$ \\
\hline $\mathrm{Au}-\mathrm{NPs}_{2.0}$ & $29.25 \mathrm{a}$ & $1.78 \mathrm{ab}$ & $5.76 \mathrm{~b}$ & $29.02 \mathrm{~b}$ & $4.88 \mathrm{~b}$ \\
\hline $\mathrm{Au}-\mathrm{NPs}_{5.0}$ & $25.31 \mathrm{ab}$ & $1.43 \mathrm{~b}$ & $5.14 \mathrm{~b}$ & $28.45 \mathrm{~b}$ & $5.69 \mathrm{a}$ \\
\hline SEM & 0.218 & 0.057 & 0.168 & 0.572 & 0.009 \\
\hline P-value & 0.027 & 0.033 & 0.049 & 0.038 & 0.016 \\
\hline \multicolumn{6}{|l|}{28 days } \\
\hline Control & $22.37 \mathrm{~b}$ & $2.12 \mathrm{a}$ & $7.04 \mathrm{a}$ & $31.88 \mathrm{a}$ & $4.98 \mathrm{~b}$ \\
\hline $\mathrm{Au}-\mathrm{NPs}_{2.0}$ & $28.12 \mathrm{a}$ & $1.89 \mathrm{ab}$ & $5.95 \mathrm{~b}$ & $28.13 b$ & $7.65 \mathrm{a}$ \\
\hline $\mathrm{Au}-\mathrm{NPs}_{5.0}$ & $18.06 \mathrm{c}$ & $1.57 \mathrm{~b}$ & $5.36 \mathrm{~b}$ & $27.04 \mathrm{~b}$ & $7.44 \mathrm{a}$ \\
\hline SEM & 0.388 & 0.035 & 0.294 & 0.278 & 0.172 \\
\hline P-value & 0.022 & 0.013 & 0.009 & 0.042 & 0.014 \\
\hline \multicolumn{6}{|l|}{ Dose effect } \\
\hline $\mathrm{Au}-\mathrm{NPs}_{2.0}$ & 27.91 & 1.79 & 6.36 & 30.13 & 4.93 \\
\hline $\mathrm{Au}-\mathrm{NPs}_{5.0}$ & 25.23 & 1.59 & 5.50 & 28.08 & 5.68 \\
\hline SEM & 0.476 & 0.041 & 0.311 & 0.654 & 0.149 \\
\hline $\mathrm{P}$-value & 0.066 & 0.038 & 0.146 & 0.072 & 0.061 \\
\hline
\end{tabular}

$\mathrm{n}=6$ (number of blood samples per group); WBC - white blood cells; RBC - red blood cells; Hb - hemoglobin; Ht - hematocrit; ESR - erythrocyte sedimentation rate; ${ }^{1}$ - days of administration; a, b, c - means with different letters within a row are significantly different at $\mathrm{P} \leq 0.05$; $\mathrm{SEM}$ - standard error of mean, treatment group abbreviations: see Table 1.

The application of AuNPs had a significant impact both on AST and ALT activity, but the effect depends on the tested dose and the time of exposure. An increase of AST activity in group Au-NPs 2.0 was observed only after 28 days of application $(\mathrm{P}=0.009)$, while in group Au-NPs ${ }_{5.0}$ after 14-days duration time $(\mathrm{P}=0.032)$. An elevation of ALT activity was noted after 21 and 28 days of AuNPs administration in 
both experimental groups $(\mathrm{P}=0.028$ and $\mathrm{P}=0.025$, respectively). In turn, application of AuNPs had no significant influence on kidney function indicators: UREA, CREAT and UA. In Au-NPs ${ }_{2.0}$ group, a significant $(\mathrm{P} \leq 0.05)$ increase of pro-oxidant indices: MDA and LOOH in blood was noted after a long-term exposure (21 and 28 days) (Table 4). In Au-NPs ${ }_{5.0}$ group it was observed already after 7 days of AuNPs supplementation $(\mathrm{P}=0.027$ and $\mathrm{P}=0.046$, respectively). The both tested doses of AuNPs contributed to a significant $(\mathrm{P} \leq 0.05)$ decrease of $\mathrm{GSH}+\mathrm{GSSG}$ concentration in chickens blood, but only at 21-28 days of experiment. An increase of SOD activity was observed after a short-term exposure to AuNPs (7-day) in both treated groups. Long-lasting (21-28 day) application of a higher dose of AuNPs caused a decrease of SOD activity $(\mathrm{P}=0.022$ and $\mathrm{P}=0.013$, respectively).

Table 4. The effect of gold nanoparticles administration to chickens on redox parameters

\begin{tabular}{|c|c|c|c|c|c|}
\hline Item & $\begin{array}{c}\text { MDA } \\
(\mu \mathrm{mol} / 1)\end{array}$ & $\begin{array}{c}\mathrm{LOOH} \\
(\mu \mathrm{mol} / \mathrm{l})\end{array}$ & $\begin{array}{c}\mathrm{GSH}+\mathrm{GSSG} \\
(\mu \mathrm{mol} / \mathrm{l})\end{array}$ & $\begin{array}{l}\text { SOD } \\
(\mathrm{U} / 1) \\
\end{array}$ & $\begin{array}{l}\text { CAT } \\
(\mathrm{U} / 1)\end{array}$ \\
\hline \multicolumn{6}{|l|}{7 days } \\
\hline Control & $0.284 \mathrm{~b}$ & $1.91 \mathrm{~b}$ & 0.064 & $25.13 \mathrm{~b}$ & 0.742 \\
\hline $\mathrm{Au}-\mathrm{NPs}_{2.0}$ & $0.275 b$ & $2.23 \mathrm{ab}$ & 0.057 & $33.94 \mathrm{a}$ & 0.753 \\
\hline $\mathrm{Au}-\mathrm{NPs}_{5.0}$ & $0.332 \mathrm{a}$ & $2.74 \mathrm{a}$ & 0.055 & $35.21 \mathrm{a}$ & 0.778 \\
\hline SEM & 0.058 & 0.071 & 0.003 & 0.895 & 0.052 \\
\hline P-value & 0.027 & 0.046 & 0.684 & 0.004 & 0.688 \\
\hline \multicolumn{6}{|l|}{14 days } \\
\hline Control & $0.297 \mathrm{~b}$ & $2.58 \mathrm{~b}$ & 0.059 & $26.82 \mathrm{~b}$ & $0.712 \mathrm{~b}$ \\
\hline $\mathrm{Au}-\mathrm{NPs}_{2.0}$ & $0.336 \mathrm{ab}$ & $2.91 \mathrm{ab}$ & 0.054 & $34.58 \mathrm{a}$ & $0.820 \mathrm{a}$ \\
\hline $\mathrm{Au}-\mathrm{NPs}_{5.0}$ & $0.370 \mathrm{a}$ & $3.73 \mathrm{a}$ & 0.050 & $30.25 \mathrm{ab}$ & $0.653 \mathrm{c}$ \\
\hline SEM & 0.054 & 0.122 & 0.004 & 0.812 & 0.039 \\
\hline P-value & 0.008 & 0.018 & 0.729 & 0.047 & 0.026 \\
\hline \multicolumn{6}{|l|}{21 days } \\
\hline Control & $0.351 \mathrm{~b}$ & $2.47 \mathrm{~b}$ & $0.073 \mathrm{a}$ & $30.34 \mathrm{a}$ & $0.689 \mathrm{~b}$ \\
\hline $\mathrm{Au}-\mathrm{NPs}_{2.0}$ & $0.469 \mathrm{a}$ & $3.51 \mathrm{a}$ & $0.042 \mathrm{~b}$ & $31.32 \mathrm{a}$ & $0.725 \mathrm{a}$ \\
\hline $\mathrm{Au}-\mathrm{NPs}_{5.0}$ & $0.509 \mathrm{a}$ & $3.70 \mathrm{a}$ & $0.037 \mathrm{~b}$ & $22.98 \mathrm{~b}$ & $0.617 \mathrm{c}$ \\
\hline SEM & 0.083 & 0.079 & 0.002 & 0.774 & 0.036 \\
\hline P-value & $<0.001$ & 0.024 & $<0.001$ & 0.022 & 0.014 \\
\hline \multicolumn{6}{|l|}{28 days } \\
\hline Control & $0.328 \mathrm{c}$ & $2.32 \mathrm{~b}$ & $0.070 \mathrm{a}$ & $31.98 \mathrm{a}$ & $0.720 \mathrm{a}$ \\
\hline $\mathrm{Au}-\mathrm{NPs}_{2.0}$ & $0.476 \mathrm{~b}$ & $3.37 \mathrm{a}$ & $0.038 \mathrm{~b}$ & $25.35 \mathrm{ab}$ & $0.607 \mathrm{~b}$ \\
\hline $\mathrm{Au}-\mathrm{NPs}_{5.0}$ & $0.551 \mathrm{a}$ & $3.92 \mathrm{a}$ & $0.033 \mathrm{~b}$ & $19.89 \mathrm{~b}$ & $0.588 \mathrm{~b}$ \\
\hline SEM & 0.036 & 0.045 & 0.002 & 0.965 & 0.028 \\
\hline P-value & $<0.001$ & 0.024 & 0.034 & 0.013 & 0.027 \\
\hline \multicolumn{6}{|l|}{ Dose effect } \\
\hline $\mathrm{Au}-\mathrm{NPS}_{2.0}$ & 0.389 & 3.00 & 0.048 & 31.05 & 0.733 \\
\hline $\mathrm{Au}-\mathrm{NPs}_{5.0}$ & 0.436 & 3.52 & 0.044 & 27.08 & 0.659 \\
\hline SEM & 0.058 & 0.024 & 0.005 & 1.018 & 0.067 \\
\hline P-value & 0.036 & 0.041 & 0.082 & 0.047 & 0.002 \\
\hline
\end{tabular}

$\mathrm{n}=6$ (number of blood samples per group); MDA - malondialdehyde; $\mathrm{LOOH}$ - lipid peroxides; GSH - reduced glutathione; GSSG - oxidized glutathione; SOD - superoxide dismutase; CAT - catalase; a, b, c - means with different letters within a row are significantly different at $\mathrm{P} \leq 0.05$; SEM - standard error of mean, treatment group abbreviations: see Table 1. 
The effect AuNPs on CAT activity was totally different depending on the tested dose and the time of nanocolloid administration. In Au-NPs ${ }_{2.0}$ group after 14 and 21 days of supplementation an increase of catalase activity was noted $(\mathrm{P}=0.026$ and $\mathrm{P}=0.014$, respectively). Extending the time of administration to 28 days has contributed to a decrease of this enzyme activity $(\mathrm{P}=0.027)$. In turn, 14-28 days of AuNPs administration for Au-NPs ${ }_{5.0}$ group resulted in a significant drop in catalase activity.

Table 5. Effect of gold nanoparticles administration to chickens on kidney and liver function indicators

\begin{tabular}{|c|c|c|c|c|c|}
\hline Item & $\begin{array}{c}\text { UA } \\
(\mu \mathrm{mol} / 1)\end{array}$ & $\begin{array}{c}\text { UREA } \\
(\mathrm{mmol} / \mathrm{l})\end{array}$ & $\begin{array}{c}\text { CREAT } \\
(\mu \mathrm{mol} / \mathrm{l})\end{array}$ & $\begin{array}{l}\text { AST } \\
(\mathrm{U} / 1)\end{array}$ & $\begin{array}{l}\text { ALT } \\
(\mathrm{U} / 1)\end{array}$ \\
\hline \multicolumn{6}{|l|}{7 days } \\
\hline Control & 265.33 & 0.768 & 21.43 & 151.12 & 5.44 \\
\hline $\mathrm{Au}-\mathrm{NPs}_{2.0}$ & 270.85 & 0.789 & 20.12 & 157.69 & 6.78 \\
\hline $\mathrm{Au}-\mathrm{NPs}_{5.0}$ & 274.88 & 0.797 & 21.67 & 171.20 & 7.45 \\
\hline SEM & 5.88 & 0.009 & 0.332 & 9.62 & 0.625 \\
\hline $\mathrm{P}$-value & 0.432 & 0.093 & 0.341 & 0.133 & 0.254 \\
\hline \multicolumn{6}{|l|}{14 days } \\
\hline Control & 253.51 & 0.731 & 24.22 & $167.22 \mathrm{~b}$ & 6.03 \\
\hline $\mathrm{Au}-\mathrm{NPs}_{2.0}$ & 251.98 & 0.698 & 26.12 & $190.12 \mathrm{ab}$ & 7.34 \\
\hline $\mathrm{Au}-\mathrm{NPs}_{5.0}$ & 260.73 & 0.725 & 25.98 & $206.98 \mathrm{a}$ & 8.11 \\
\hline SEM & 4.25 & 0.011 & 0.298 & 9.75 & 0.481 \\
\hline P-value & 0.127 & 0.123 & 0.225 & 0.032 & 0.471 \\
\hline \multicolumn{6}{|l|}{21 days } \\
\hline Control & 278.31 & 0.847 & 27.88 & $175.13 \mathrm{~b}$ & $6.52 \mathrm{~b}$ \\
\hline $\mathrm{Au}-\mathrm{NPs}_{2.0}$ & 285.02 & 0.862 & 26.76 & $198.34 \mathrm{ab}$ & $9.15 \mathrm{a}$ \\
\hline $\mathrm{Au}-\mathrm{NPS}_{5.0}$ & 289.77 & 0.839 & 28.23 & $214.45 \mathrm{a}$ & $9.96 \mathrm{a}$ \\
\hline SEM & 5.32 & 0.016 & 0.342 & 11.87 & 0.452 \\
\hline P-value & 0.245 & 0.090 & 0.120 & 0.015 & 0.028 \\
\hline \multicolumn{6}{|l|}{28 days } \\
\hline Control & 288.45 & 0.905 & 27.12 & $165.44 \mathrm{c}$ & $6.98 \mathrm{~b}$ \\
\hline $\mathrm{Au}-\mathrm{NPs} 2.0$ & 297.88 & 0.913 & 27.87 & $198.52 \mathrm{~b}$ & $10.87 \mathrm{a}$ \\
\hline Au-NPs5.0 & 290.54 & 0.877 & 28.54 & $255.51 \mathrm{a}$ & $11.76 \mathrm{a}$ \\
\hline SEM & 4.95 & 0.019 & 0.402 & 10.98 & 0.772 \\
\hline $\mathrm{P}$-value & 0.251 & 0.198 & 0.228 & 0.009 & 0.025 \\
\hline \multicolumn{6}{|l|}{ Dose effect } \\
\hline Au-NPs 2.0 & 276.43 & 0.816 & 25.24 & 184.92 & 8.54 \\
\hline Au-NPs5.0 & 278.98 & 0.810 & 26.11 & 212.04 & 9.32 \\
\hline SEM & 3.77 & 0.008 & 0.219 & 11.92 & 0.677 \\
\hline $\mathrm{P}$-value & 0.155 & 0.151 & 0.103 & 0.024 & 0.168 \\
\hline
\end{tabular}

$\mathrm{n}=6$ (number of blood samples per group), UREA - urea, UA - uric acid, CREAT - creatinine, AST - aspartate aminotransferase, ALT - alanine aminotransferase; a ,b, c - means with different letters within a row are significantly different at $\mathrm{P} \leq 0.05 ; \mathrm{SEM}$ - standard error of mean, treatment group abbreviations: see Table 1 . 


\section{Discussion}

The results of the experiment indicate that the application of AuNPs had no negative effect on the survival rate of the birds, and furthermore, no abnormal changes in behaviour were observed in the AuNPs-treated birds. However, early in the experiment the chickens receiving a dose of $5.0 \mathrm{mg} / \mathrm{kg}$ were already responding with a reduced body weight gains as compared to the control. This tendency increased with the length of administration of AuNPs and in consequence the experimental chickens gained $6 \%$ less weight than the control birds. Administration of the lower dose of AuNPs, i.e. $2.0 \mathrm{mg} / \mathrm{kg}$, had a less pronounced effect on body weight gains, but at the end of the experiment they were significantly reduced. A study by Pineda et al. (2012) and Sawosz et al. (2010) on chicken embryos indicated that in ovo injection of AuNPs ( $0.3 \mathrm{ml}, 50 \mathrm{ppm}$ concentration) neither promoted nor depressed their growth and development. According to Chen et al. (2009), the unwanted effects observed as a result of administration of AuNPs to mice $(8 \mathrm{mg} / \mathrm{kg} / \mathrm{week}$, intraperitoneal injection for 28 days) included fatigue, a change in fur color, appetite loss and weight loss, with toxic effects found to be highly dependent on the size of the particles. Mice injected with 3, 5, 50, and $100 \mathrm{~nm}$ AuNPs did not exhibit symptoms of intoxication, whereas they appeared in mice receiving 8-37 nm nanoparticles. Rats receiving AuNPs per os (5-15 nm diameter, 14 days) at doses of 375-1,300 $\mu \mathrm{g} / \mathrm{kg}$ exhibited no changes in body weight or relative weight of organs during the treatment (Jo et al., 2015). Mice receiving AuNPs per os for 14 days at a dose of $550-2.200 \mu \mathrm{g} / \mathrm{kg}$ responded with a decrease in weight gains but they did not show any apparent signs of intoxication (Zhang et al., 2010). The studies cited also analyzed the biological effects of application of AuNPs at a dose of $1,100 \mu \mathrm{g} / \mathrm{kg}$ for 28 days depending on the route of administration. A pronounced negative effect on the growth of mice and on blood parameters was observed in the case of oral administration, while subcutaneous administration only slightly reduced body weight gains and tail vein injection was well tolerated. The reasons for the increased toxicity in the case of oral administration lie in the destructive effect of NPs on the intestinal mucosa and thus reduced absorption of nutrients. Another study by the same authors (Zhang et al., 2011), which tested the effects of subcutaneous application of PEGcoated AuNPs to mice at a dose of $4 \mathrm{mg} / \mathrm{kg}(5,10,30,60 \mathrm{~nm}$ diameter, 28 days), showed that they did not affect mortality rates or did not have a negative effect on body weight gains. The results of study by Lasagna-Reeves et al. (2010) confirmed low toxicity of AuNPs for intraperitoneal injection in a dose range of 320-3,200 $\mu \mathrm{g}$ / $\mathrm{kg}$. These researchers analyzed survival rate, behaviour, growth, organ morphology and blood biochemistry.

Due to intensive cell proliferation, the hematopoietic system and peripheral blood cells are particularly sensitive to the presence of chemical substances. After entering the bloodstream NPs come into direct contact with blood cells, and thus interactions between them are very likely. The hematological analysis has revealed that in the group receiving AuNPs at a rate of $5.0 \mathrm{mg} / \mathrm{kg}$, after just 14 days of administration the erythrocyte count was reduced considerably, and statistically significant differences with respect to the control were observed after 21 and 28 days of the 
administration of the nanocolloid. This was accompanied by a decrease in other red blood cell indicators, i.e. the $\mathrm{Hb}$ level and $\mathrm{Ht}$ value. NPs absorbed by neutrophils or monocytes chronically stimulate respiratory burst, which can lead to a local or even a systemic inflammatory reaction (Małaczewska, 2015). Oxygen radicals generated during this process may cause adverse changes within various blood cells, i.e. erythrocytes and platelets. The most common phenomenon observed as a result of exposure to various NPs is hemolysis of erythrocytes, contributing to the occurrence of hemolytic anemia (Abdelhalim and Moussa, 2012; Chen et al., 2015). On the other hand, an increase in RBC count has also been observed following administration of AuNPs which according to the authors is explained by their beneficial effect on the hemopoiesis process through stimulation of erythropoietin secretion (Ziaee Ghahnavieh et al., 2014). The decline in red blood cell indicators observed in our study during the longer application of AuNPs may indicate a negative effect on the erythrocyte life span or an inhibitory influence on myeloid hemopoiesis processes. Bone marrow, as an organ with intensive metabolism, is highly susceptible to the effects of various chemical substances, such as medicines. They can cause toxic damage leading to bone marrow failure and the development of aplastic anemia, which has been reported in the case of application of gold salts (Maj, 2000). Other causes of anemia include iron deficiency. Our previous research (Sembratowicz et al., 2016) showed that AuNPs can accumulate in the intestines and block the absorption of some macroand micronutrients, including iron.

Some studies indicate a direct interaction between NPs and white blood cells, both granulocytes (cells with phagocytic capacity) and lymphocytes (Wiwanitkit et al., 2010; Leroy et al., 2011). NPs absorbed by granulocytes may contribute to their apoptosis, leading to a reduction in their numbers in the blood, although they are partially replaced by immature forms, which are not, however, fully immunocompetent (Jovanović and Palić, 2012). This is an unwanted phenomenon, as it increases susceptibility to infectious diseases and even cancer. On the other hand, NPs may accumulate in hemopoeitic bone tissue contributing to leukopoesis and megacariopoesis (Berce et al., 2016). The results of our study indicate that both tested doses of AuNPs already after 7-14 days of administration, caused an increase in WBC count, but prolonged supplementation with a higher dose had a negative impact on these cells count. This may be linked to failure (aplasia) of the bone marrow as a consequence of a long-term exposure to NPs, or induction of apoptosis in leukocytes, as described above. Abdelhalim and Moussa (2012) noted a decrease in WBC count and the percentage of neutrophils as a result of intraperitoneal injection of 10 $\mathrm{nm}$ AuNPs, whereas administration of $50 \mathrm{~nm}$ particles had no effect on these parameters. Interaction of NPs with immune cells may trigger an inflammatory response, manifested by an increased production of pro-inflammatory mediators (TNF- $\alpha$, interleukins) (Sembratowicz and Ognik, 2018). An evaluation of pro-inflammatory properties of nanoparticles is very important from a point of view of their further application. The study conducted by Sawosz et al. (2010) in which AuNPs were administered in ovo confirmed that they did not induce inflammatory reaction, while $\mathrm{Ag} / \mathrm{Cu}$ nanoparticles revealed pro-inflammatory activity. Changes in the proportions of serum proteins during inflammation (an increase in globulins and fibrinogen and 
a decrease in albumins) result in more rapid erythrocyte sedimentation (Lis, 2012). It is worth noting that in AuNPs-treated chickens a significant increase in the erythrocyte sedimentation rate (ESR) was observed. However, it may be a consequence not only of an inflammatory response, but always a decrease of RBC count.

Measuring indicators of induction of oxidative stress is one means of testing the systemic toxicity of NPs (Sarkar et al., 2014). The results of our study have shown that the oral administration of AuNPs at both doses tested induced oxidative stress, as indicated by the elevated levels of malondialdehyde and LOOH in blood. Malondialdehyde is a lipid peroxidation end product and its concentration in the blood is a non-specific marker of oxidative stress. In the case of the higher dose of AuNPs $(5.0 \mathrm{mg} / \mathrm{kg})$, the increase in these parameters occurred sooner (after 7 days) than in the case of the lower dose $(2.0 \mathrm{mg} / \mathrm{kg})$, and intensified with the duration of administration.

Due to increased lipid peroxidation new radical forms are continually produced, which may result in depletion of endogenous antioxidants, e.g. glutathione. This compound is largely known to minimize the lipid peroxidation of cellular membranes by removing of hydrogen peroxide in reaction catalyzed by glutathione peroxidase. It is worth noting that total glutathione (GSH+GSSG) content in the body consists of its reduced fraction, accounting for $98 \%$ of the total concentration, and of the oxidized fraction. During oxidative and nitrosative stress the glutathione level decreases as a consequence of its oxidation and forming of S-conjugates. The enzymes responsible for GSH synthesis may also be damaged by radicals and the de novo synthesis occurs too slowly (Bilska et al., 2007). The results of our study have revealed that long-term (21-28 day) exposure to AuNPs contributed to a decrease in the GSH+GSSG content in blood. This should be considered a highly adverse phenomenon because this compound is involved not only in free radical reactions, but also in the coupling (detoxification) of numerous xenobiotics.

The changes in the activity of the antioxidant enzymes: SOD and CAT under the influence of metallic NPs has been shown in studies by various authors (Ahmadi, 2012; Ognik et al., 2016). In general, information regarding oxidative stress caused by AuNPs is conflicting. Some researchers have reported that AuNPs reveal prooxidant properties and generate oxidative stress (Cho et al., 2009; Jia et al., 2009; Yah, 2013), while others have observed no significant induction of oxidative stress or inflammatory response (Nelson et al., 2013). Some studies have even noted antioxidant and anti-inflammatory activity of AuNPs (Shukla et al., 2005; Sumbayev et al., 2013). BarathManiKanth et al. (2010) showed that 15-day injection of AuNPs $(50 \mathrm{~nm}, 2.5 \mathrm{mg} / \mathrm{kg})$ to experimentally diabetic mice reduces complications of diabetes by stimulating the activity of antioxidant enzymes: SOD, CAT and GPx, which effectively eliminate ROS responsible for its serious complications. Varied and at times conflicting results are undoubtedly due in part to different experimental conditions, including dosage, length of administration, and the properties of the nanoparticles themselves. The results of our experiment show that initially, i.e. after 7 and 14 days of administration of AuNPs, SOD activity increased in both experimental groups. It may be an expression of an adaptive response to increased ROS formation induced by the nanoparticles. Among antioxidant enzymes it is SOD that is consid- 
ered the "induced" enzyme, whose activity is stimulated through substrate induction, by an excess of superoxide radical. However, longer administration period, particularly in the case of the higher dose $(5.0 \mathrm{mg} / \mathrm{kg})$, resulted in a decrease in SOD and CAT activity. It has been established that AuNPs, like AgNPs, exhibit high affinity for thiol groups of proteins and can easily bind with them, which may negatively affect their functions, such as enzyme activity (Adayemi and Whiteley, 2014). It is also likely that NPs can easily oxidize thiol groups of glutathione, resulting in a smaller pool of reduced glutathione.

The liver is the main site for biodistribution and metabolism of AuNPs, irrespective of the means of administration, and thus this organ is highly susceptible to their harmful effects (Cho et al., 2009). In connection with their function of removing foreign particles from the peripheral blood, hepatic macrophages (Kupffer cells) detect and engulf NPs, which results in their stimulation and production of pro-inflammatory mediators, inducing not only a local immune response but a systemic response as well (Chen et al., 2009). AuNPs have been shown to contribute to various histopathological changes in the liver, such as hydropic degeneration, cloudy swelling, fatty degeneration and chronic inflammation (Abdelhalim and Jarrar, 2012). According to Kasarala and Tillman (2016) standard tests that assess toxic or infectious injury to the liver include ALT, AST, and alkaline phosphatases (APs). To evaluate a possible hepatotoxic effect of AuNPs, we tested the activity of ALT and AST. Both aminotransferases are highly concentrated in the liver, AST is also represented in the heart, skeletal muscle, kidneys, brain and red blood cells, and ALT has low concentrations in skeletal muscle and kidney. Therefore, an increase in ALT blood levels is more specific for liver damage (Gianini et al., 2005). Hepatocyte injury results in altered cell membrane permeability contributing the excessive leakage of aminotransferases. Our study has shown that the both tested doses of AuNPs caused an increase in the activity of aminotransferases. A stronger effect, indicating more serious hepatocytes damage, was shown for the higher dose of AuNPs, especially during the longer period of administration. A slight elevation of aminotransferases activity was observed already after 7 days of administration of AuNPs, which seems to confirm that the liver is highly sensitive to the presence of nanoparticles. However, unlike the ALT that is found mainly in the liver, AST is also present in other tissues, so an elevated AST activity cannot be the reason for hepatocytes injuries only.

To detect an influence of AuNPs on kidney function, plasma level of UREA, CREAT and UA was determined. Increased blood UA concentration along with increased UREA and CREAT suggests an impaired kidney function in both mammals and birds (Valchev et al., 2014). In some studies major toxicity of AuNPs in the kidneys has not been observed (Lasagna-Reeves et al., 2010; Abdelhalim and Moussa, 2013; Jo et al., 2015) but in other experiments their nephrotoxic activity has been revealed (Abdelhalim and Jarrar, $2011 \mathrm{a}, \mathrm{b}$ ). However, the size of the particles plays an important role in this regard. Yang et al. (2014) showed that small particles (4.5 nm) were excreted quickly through urine, while bigger ones $(30 \mathrm{~nm})$ had a more blood circulation time and higher organ accumulation. The results of our study have shown that AuNPs did not significantly affect CREAT, UA and UREA contents in blood plasma of chickens even during long-lasting administration. It might be related to 
the high clearance of AuNPs through kidney and in consequence small accumulation in this organ.

\section{Conclusions}

Administration of the lower dose of ANPs $(2.0 \mathrm{mg} / \mathrm{kg} / \mathrm{b}$.w.) for 14 days did not cause toxicological effects for chickens, but extending the duration time caused growth inhibition, hematological alterations and an increase in liver injury indicators. The higher dose $(5.0 \mathrm{mg} / \mathrm{kg} / \mathrm{b}$.w. $)$ of ANPs showed greater toxicity, and adverse effects on growth and blood indices appeared already after 7-14 days of supplementation. These findings provide useful information about the possibility of using AuNPs for poultry, but further research, involving their bioaccumulation in organs and histopathological studies is needed.

\section{References}

A bdelhalim M.A.K., Jarrar B.M. (2011 a). Renal tissue alterations were size-dependent with smaller ones induced more effects and related with time exposure of gold nanoparticles. Lip. Health Dis., 10: 163.

A bde $1 \mathrm{~h}$ a $1 \mathrm{i}$ m M.A.K., J a r r a r B.M. (2011 b). The appearance of renal cells cytoplasmic degeneration and nuclear destruction might be an indication of GNPs toxicity. Lip. Health Dis., 10: 147.

A bde $1 \mathrm{~h}$ a $1 \mathrm{im}$ M.A.K., J a r a r B.M. (2012). Histological alterations in the liver of rats induced by different gold nanoparticle sizes, doses and exposure duration. J. Nanobiotechnol., 10: 5.

A b d e $1 \mathrm{~h}$ a $1 \mathrm{im}$ M.A.K., M o u s a S.A.A. (2012). The dimensional hematological alterations induced in blood of rats in vivo by intraperitoneal administration of gold nanoparticles. J. Nanomed. Nanotechnol., 3: 138 .

A b d e lhali m M.A.K., M o u s s a S.A.A. (2013). The gold nanoparticle size and exposure duration effect on the liver and kidney function of rats: in vivo. Saudi J. Biol. Sci., 2: 177-181.

A d a y e m i O.S., W hit e le y C.G. (2014). Interaction of metal nanoparticles with recombinant arginine kinase from Trypanosoma brucei: Thermodynamic and spectrofluorimetric evaluation. Bioch. Biophys. Acta, 1840: 701-706.

A h m a d i F. (2012). Impact of different levels of silver nanoparticles (Ag-NPs) on performance, oxidative enzymes and blood parameters in broiler chicks. Pak. Vet. J., 32: 325-328.

A 1 k i 1 a n y A.M., M u r p h y C.J. (2010). Toxicity and cellular uptake of gold nanoparticles: what we have learned so far? J. Nanopart. Res., 12: 2313-2333.

BarathManiKanth S., Kalishwaralal K., Sriram M., Pandian S.R.K., Youn H., E o m S., Gu ru n a th a n S. (2010). Anti-oxidant effect of gold nanoparticles restrains hyperglycemic conditions in diabetic mice. J. Nanobiotechnol., 8: 16.

B artos z G. (2004). Second face of oxygen (in Polish). Polish Scientific Publishers PWN, Warsaw, pp. 376-378.

B erce C., Luc an C., Petrushev B., B oc a S., Micle an M., S arpataki O., A stile an S., Buzoianu A., Tomuleasa C., Bojan A. (2016). In vivo assessment of bone marrow toxicity by gold nanoparticle-based bioconjugates in Crl:CD1(ICR) mice. Int. J. Nanomed., 1: 4261-4273.

B i 1 s k a A., Kry c z y k A., W ł od e k L. (2007). The different aspects of the biological role of glutathione (in Polish). Post. Hig. Med. Dosw., 61: 428-453.

Ch en L.Q., F a n g L., L in g J., D in g C.Z., K a n g B., H u a n g C.Z. (2015). Nanotoxicity of silver nanoparticles to red blood cells: size dependent adsorption, uptake, and hemolytic activity. Chem. Res. Toxicol., 28: 501-509.

Chen Y.S., H ung Y.C., Li a u I., H u ang G.S. (2009). Assessment of the in vivo toxicity of gold nanoparticles. Nanoscale Res. Lett., 4: 858-864.

Cho W.S., Cho M., Jeong J., Choi M., Cho H.Y., Han B.S., Kim S.H., Kim H.O., 
L i m Y.T., Chung B.H., J e ong J. (2009). Acute toxicity and pharmacokinetics of $13 \mathrm{~nm}$-sized PEG-coated gold nanoparticles. Tox. Appl. Pharmacol., 236: 16-24.

Connor E.E., Mwa muka J., Gole A., Murphy C.J., Wy a t t M.D. (2005). Gold nanoparticles are taken up by human cells but do not cause acute cytotoxicity. Small, 1: 325-327.

Dobrovolskaia M.A., Patri A.K., Zheng J., Flogston J.D., Ayub N., Aggarwal P. (2009). Interaction of colloidal gold nanoparticles with human blood: effects on particle size and analysis of plasma protein binding profiles. Nanomedicine, 5: 106-117.

D y k m a n L., K h l e b t s o v N. (2017). Immunological properties of gold nanoparticles. Chem. Sci., 8: $1719-1735$.

G a y C.A., Gę bi cki J.M. (2002). Perchloric acid enhances sensitivity and reproducibility of the ferric-xylenol orange peroxide assay. Anal. Biochem., 304: 42-46.

Gi a n in i E.G., Te st a R., S a v ar in o V. (2005). Liver enzyme alterations: a guide for clinicians. CMAJ, 271: 367-379.

Ji a H.Y., Li u Y., Zhang X.J., H an L., D u L.B., Ti an Q., X u Y.C. (2009). Potential oxidative stress of gold nanoparticles by induced-NO releasing in serum. J. Am. Chem. Soc., 131: 40-41.

J o M.R., B a e S.H., G o M.R., K i m H.J., H w a n g Z.G., C h o i S.J. (2015). Toxicity and biokinetics of colloidal gold nanoparticles. Nanomaterials, 5: 835-850.

Jovanović B., Palić D. (2012). Immunotoxicology of non-functionalized engineered nanoparticles in aquatic organisms with special emphasis on fish - review of current knowledge, gap identification, and call for further research. Aquatic Toxicol., 118/119: 141-151.

K a s a r la G., Till m a n M.D. (2016). Standard liver tests. Clin. Liver Dis., 8: 13-18.

Las a gna-Reeves C., Gonzalez-R o mero D., B arria M.A., Olmedo I., C lo s A., R a manuj a m V.M.S.A., Ur a y a m a A., Vergara L., Kogan M.J., S o to C. (2010). Bioaccumulation and toxicity of gold nanoparticles after repeated administration in mice. Bioch. Bioph. Res. Comm., 393: 649-655.

L eroy P., Sapin-Minet A., P it a r ch A., B oudier A., Tournebize J. (2011). Interaction between gold nanoparticles and macrophages: activation or inhibition? Nitric Oxide, 25: 54-56.

Li X., Robinson S.M., Gupta A., Saha K., Jiang Z., Moyano D.F., Sahar A., Ri 1 e y M.A., Rote 11 o V.M. (2014). Functional gold nanoparticles as potent antimicrobial agents against multi-drug-resistant bacteria. ACS Nano, 8: 10682-10686.

L is K. (2012). Erythrocyte sedimentation rate in the past and present day (in Polish). J. Lab. Diag., 48: 213-218.

M a j S. (2000). Drug-induced blood dyscrasias (in Polish). Post. Nauk Med., 4: 17-28.

M a ł a c z e w s k a J. (2015). Effect of oral administration of commercial gold nanocolloid on peripheral blood leukocytes in mice. Pol. J. Vet. Sci., 18: 273-282.

Nel A., Xi a T., Mädle r L., Li N. (2006). Toxic potential of materials at the nanolevel. Science, 311: 622-627.

Nelson B.C., Petersen E.J., Marquis B.J., A tha D.H., Elliott J.T., Cleveland D., Wat s on S.S., Ts eng I.H., Dillon A., Theodore M., J a c kman J. (2013). NIST gold nanoparticle reference materials do not induce oxidative DNA damage. Nanotoxicology, 7: 21-29.

Ognik K., Cholewińska E., Czech A., Kozłowski K., Wlazło Ł., Nowakowicz- D ębek B., Szlązak R., Tutaj K. (2016). Effect of silver nanoparticles on the immune, redox, and lipid status of chicken blood. Czech J. Anim. Sci., 61: 450-461.

Pan Y., Leifert A., Ruau D., Neus s S., Bornemann J., Schmid G., Brandau W., S imon U., Jahnen-De chen W. (2009). Gold nanoparticles of diameter $1.4 \mathrm{~nm}$ trigger necrosis by oxidative stress and mitochondrial damage. Small, 5: 2067-2076.

P in ed a L., S a w o s z E., Hotowy A., Eln if J., S aw o s z F., A li A., Chw a libog A. (2012). Effect of nanoparticles of silver and gold on metabolic rate and development of broiler and layer embryos. Comp. Bioch. Physiol., Part A, 161: 315-319.

S a lih M., S m ith D.M., Pric e J.F., D aw s o n L.E. (1987). Modified extraction 2-thiobarbituric acid method for measuring lipid oxidation in poultry. Poultry Sci., 66: 1483-1488.

S a p t a r s h i S.R., D u s c h 1 A., L o p a t a A.L. (2013). Interaction of nanoparticles with proteins: relation to bio-reactivity of the nanoparticles. J. Nanobiotechnol., 11: 26.

S a rkar A., Gh o sh M., S i 1 P.C. (2014). Nanotoxicity: Oxidative stress mediated toxicity of metal and metal oxide nanoparticles. J. Nanosci. Nanotechnol., 14: 730-743. 
S aw os z E., Grodzik M., Lis ow ski P., Zwierzchowski L., Ni e mi e c T., S zmidt M., $\mathrm{Chw}$ a lib og A. (2010). Influence of hydrocolloids of $\mathrm{Ag}, \mathrm{Au}$, and $\mathrm{Ag} / \mathrm{Cu}$ alloy nanoparticles on the inflammatory state at transcriptional level. Bull. Vet. Inst. Pulawy, 54: 81-85.

Schrand A.M., Braydich-Stolle L.K., Schlager J.J., Dai L., Hussain S.M. (2008). Can silver nanoparticles be useful as potential biological labels? Nanotechnology, 19: 1-13.

S e mbratowicz I., Ognik K. (2018). Immunotropic activity of gold nanocolloid in chickens. J. Trace El. Med. Biol., 47: 98-103.

S e mbratowicz I., Ognik K., Stępniowska A. (2016). An evaluation of in vitro intestinal absorption of iron, calcium and potassium in chickens receiving gold nanoparticles. Brit. Poultry Sci., 57: 559-565.

S engupta J., D a t t a P., P atra H.K., D a s gupta A.K., Gomes A. (2013). In vivo interaction of gold nanoparticles after acute and chronic exposure in experimental animal models. J. Nanosci. Nanotechnol., 13: 1660-1670.

Sh a mail a S., Z a fer N., Riaz S., Shariff R., N a z ir J., N a s e e m S. (2014). Gold nanoparticles: an efficient antimicrobial agent against enteric human bacterial pathogens. Nanomaterials, 6: 71 .

Shukla R., Bansal V., Chaudhary M., B a s u A., Bhonde R.R., S a stry M. (2005). Biocompatibility of gold nanoparticles and their endocytotic fate inside the cellular compartment: a microscopic overview. Langmuir, 21: 10644-10654.

S i d d i qi K.S., H u s en A. (2017). Recent advances in plant-mediated engineered gold nanoparticles and their application in biological system. J. Trace El. Med. Biol., 40: 10-23.

S mulikows ka S., Rutkows ki A. (2005). Nutrient requirements of poultry, 4th rev. ed. (in Polish). The Kielanowski Institue of Anim. Physiol. Nutr. PAS.

Sumbayev V.V., Yas inska I.M., Garcia C.P., Gilliland D., Lall G.S., Gibbs B.F., B ons a 11 D.R., Varani L., R os si F., Cal zol a i L. (2013). Gold nanoparticles downregulate interleukin-1 $\beta$-induced pro-inflammatory responses. Small, 9: 472-477.

S u r e k h a K. (2017). Gold nanoparticles: their application as antimicrobial agents and vehicles of gene delivery. Adv. Biotechnol. Microbiol., 4: 555658.

Unfried K., Albrecht C., Klotz L.O., Mikecz A., Grether-Beck S., Schins R.P.F. (2007). Cellular responses to nanoparticles: target structures and mechanisms. Nanotoxicology, 1 : 52-71.

Valchev I., Kanakov D., Hristov T., Lazarov L., Binev R., Grozeva N., Nikolov Y. (2014). Effects of experimental aflatoxicosis on renal function in broiler chickens. Bulg. J. Vet. Med., 17: 314-324.

W iw a n it k it V., S e r e e m a s pun A., R o j a n a th a n e s R. (2010). Identification of gold nanoparticle in lymphocytes: a confirmation of direct intracellular penetration effect. Turk. J. Hematol., 26: 28-30.

X u Y., Tang H., Li u J.H., Wang H., Li u Y. (2013). Evaluation of the adjuvant effect of silver nanoparticles both in vitro and in vivo. Toxicol. Lett., 219: 42-48.

Y a h C.S. (2013). The toxicity of gold nanoparticles in relation to their physicochemical properties. Biomed. Res., 24: 400-413.

Yang H., D u L., Ti an X., F an Z., S un C., Li u Y. (2014). Effects of nanoparticle size and gestational age on maternal biodistribution and toxicity of gold nanoparticles in pregnant mice. Toxicol. Lett., 230: 10-18.

Zhang X.D., Wu H.Y., Wu D., Wang X.Y., Chang J.H., Zhai Z.B., Meng A.M., Liu P.X., Z hang L.A., F an F.Y. (2010). Toxicologic effects of gold nanoparticles in vivo by different administration routes. Int J. Nanomed., 5: 771-781.

Zh ang X.D., W u D., S h e n X., Li u P.X., Y ang N., Z h a o B., Z h a ng H., S un Y.M., Z h a ng L., F a n F.Y. (2011). Size-dependent in vivo toxicity of PEG coated gold nanoparticles. Int. J. Nanomed., 6: 2071-2081.

Ziaee Ghahnavieh M., Ajdary M., Ziaee Ghahnavieh M., Naghsh N. (2014). Effects of intraperitoneal injection of gold nanoparticles in male mice. Nanomed. J., 1: 121-127.

Zielińska M., Saw osz E., Grodzik M., B a lcerak M., Wierzbicki M., Skomiał J., S aw os z F., Chwa libog A. (2011 a). Effect of taurine and gold nanoparticles on the morpho- 
logical and molecular characteristics of muscle development during chicken embryogenesis. Arch. Anim. Nutr., 66: 1-13.

Zi elińsk a M., S a w o sz E., Grodzik M., Wi erzbicki M., Gromadka M., Hotowy A., Sawosz F., Lozicki A., Chwalibog A. (2011 b). Effect of heparan sulfate and gold nanoparticles on muscle development during embryogenesis. Int. J. Nanomed., 6: 3163-3172.

Zolnik B.S., González-Fernández Á., Sadrieh N., Dobrovolskaia M.A. (2010). Nanoparticles and the immune system. Endocrinology, 151: 458-465.

Received: 11 X 2018

Accepted: 12 XII 2018 